\title{
DÉFICIT NA DRENAGEM URBANA: buscando o entendimento e contribuindo para a definição
}

Vladimir Caramori Borges de Souza

Doutor em Recursos Hídricos e Saneamento Ambiental/UFRGS. Centro de Tecnologia da Universidade Federal de Alagoas. (vcaramori@yahoo.com)

\section{Luiz Roberto Santos Moraes}

PhD em Saúde Ambiental/University of London-UK. Departamento de Engenharia Ambiental da Escola Politécnica da Universidade Federal da Bahia. (moraes@ufba.br)

\section{Patrícia Campos Borja}

Doutora em Arquitetura e Urbanismo/UFBA. Departamento de Engenharia Ambiental da Escola Politécnica da Universidade Federal da Bahia. (borja@ufba.br)

\section{Resumo}

A abordagem tradicional brasileira sobre a drenagem urbana indica que os corpos d'água devem ser saneados; e, nesse aspecto, sanear tem sido entendido como drenar, no sentido de criar estruturas de micro e macrodrenagem para conduzir a água aos pontos mais distantes possíveis. Em uma visão moderna, o sistema de drenagem deve ser tratado como um dos componentes do espaço urbano, sendo impossível dissociá-lo da infraestrutura das cidades. Para avaliar esses sistemas, os indicadores tradicionais (tais como aqueles baseados em cobertura de rede ou atendimento per capita) não são capazes de retratar sua condição (eficiência ou déficit). Esse artigo busca definir o conceito de déficit em drenagem e manejo de águas pluviais urbanas, tentando estabelecer as relações entre o conceito em si, as noções de risco utilizadas em dimensionamento de redes, a cobertura do sistema, as tecnologias para drenagem das águas pluviais, a informação disponível, o estado (de degradação) dos corpos d'água e as estruturas técnico-institucionais. Observa-se que a definição conceitual de déficit relacionado às águas pluviais é complexa e se relaciona a vários aspectos da infraestrutura e da política urbanas, não podendo estar restrita à cobertura de rede.

Palavras-chave: Manejo de águas pluviais, déficit em drenagem urbana, águas urbanas.

\section{Abstract}

The traditional approach in Brazilian urban drainage suggests that water bodies should have their conveyance improved (with micro and macro drainage structures) in order to carry, as fast as possible, water out of the cities. In a modern view, it was realized that drainage system is part of urban landscape, not only by technical reasons related to hydraulic conveyance, but also by improving or degrading life quality. To evaluate these systems, traditional indicators (based on network coverage or per capita attendance) are not able to represent their efficiency or deficit. This paper proposes a new approach to define the deficit concept related to urban drainage systems. It is established the relationships between the concept itself, the risk notion used in drainage design, the network coverage, the technologies used in stormwater management, the available information, the of water quality aspects and the technical and institutional structures. It was observed that the concept of deficit related to stormwater is complex and it concerns to various aspects of urban infrastructure and urban policy that can not be restricted to network coverage.

Keywords: Stormwater management, deficit in urban drainage systems, urban waters. 


\section{INTRODUÇÃO}

A abordagem tradicional sobre o sistema de drenagem urbana, representada no Brasil pela busca de um sistema hidráulico mais eficiente, resulta da necessidade de sempre drenar o ambiente. As águas urbanas são consideradas indesejadas em função do seu alto grau de degradação e, portanto, os corpos d'água devem, de acordo com tal visão, ser submetidos a obras de retificação, canalização e recobrimento. Sanear o ambiente, no que se refere à drenagem pluvial, tem sido entendido como drenar, no sentido de criar estruturas (micro e macro) para conduzir a água aos pontos mais distantes possíveis.

Essa abordagem resulta do próprio conceito de sistema de drenagem urbana adotado no Brasil, presente na maioria dos manuais de drenagem urbana, como o conjunto de elementos destinados a recolher as águas pluviais precipitadas sobre uma determinada região e que escorrem sobre sua superfície, conduzindo-as a um destino final. Segundo Botelho (1998, p. 75), os sistemas de drenagem pluvial devem ser dimensionados com base na máxima "pegar e largar rápido", ou seja, recolher as águas da chuva e conduzi-las para jusante o mais rapidamente possível. Nesse sentido, as cidades são espaços de negação da natureza, como discutem Carvalho e Braga (2009), não sendo considerados aspectos da dinâmica natural que poderiam ser mais facilmente resolvidos pela simples observância de instrumentos legais, como o Código Florestal Brasileiro ${ }^{1}$ (BRASIL, 1965). Observa-se, portanto, uma grande distância entre os ideais da sustentabilidade, os instrumentos da política urbana e a prática da Engenharia, no que se refere às águas urbanas.

Numa perspectiva moderna, o sistema de drenagem deve ser visto como um dos componentes do espaço urbano, uma vez que é impossível dissociá-lo da infraestrutura das cidades. O sistema de drenagem de águas pluviais compõe a paisagem urbana, promovendo

${ }^{1}$ Apesar de o Código Florestal Brasileiro (Lei no 4.771/1965) ter sido revogado pela Lei $n^{0} 12.651 / 2012$ (BRASIL, 2012), a referência a ele se justifica em função de o estado atual dos sistemas de drenagem urbana ser decorrente do processo histórico de ocupação das cidades e, no caso, a Lei atual ainda não influenciou as intervenções no espaço. sua valorização (quando bem integrada ao urbanismo) ou sua degradação (quando o sistema de drenagem está degradado). Neste sentido, seu conceito deve ser ampliado, não estando representado apenas pelos elementos de infraestrutura. Em uma abordagem com foco na sustentabilidade, o conceito de drenagem urbana pode ser entendido como o "conjunto de medidas que tem como finalidade a minimização dos riscos aos quais a sociedade está sujeita e a diminuição dos prejuízos causados pelas inundações, possibilitando o desenvolvimento urbano da forma mais harmônica possível, articulado com as outras atividades urbanas" (PORTO et al., 1997, p. 805).

Com essa nova visão, ou seja, que os problemas são integrados e que, portanto, as políticas públicas também deveriam ser, a degradação do ambiente se destaca. Alguns autores, como Chebbo et al. (2001), na França, e Ide (1984), Neves (2006) e Pimentel (2009), no Brasil, apresentaram estudos para avaliar a qualidade das águas no sistema de drenagem pluvial, ficando evidente a relação entre as águas pluviais e os outros componentes do saneamento básico, com destaque para a presença significativa de resíduos sólidos, que exercem papel importante no mau funcionamento das redes de drenagem, e para o esgotamento sanitário, cuja mistura nos corpos d'água urbanos provoca a degradação das águas e cria um importante argumento para sua canalização.

Um aspecto interessante a ser observado é que as novas estratégias de manejo das águas pluviais (WSUD, LID e SUDS) surgiram a partir dos anos 1990 como necessidade de tratamento da água de escoamento. O controle de vazões de pico era objetivo secundário, como destacado por Burns et al. (2012), em uma clara referência à relação entre os diferentes componentes do saneamento básico.

Por outro lado, diferentes indicadores relacionados ao saneamento básico têm sido utilizados para diagnosticar o percentual de atendimento e a qualidade do serviço prestado à sociedade, especialmente os de água, esgotos e resíduos sólidos (BRASIL, 2010b). No que se refere ao déficit em saneamento básico, o Panorama do Saneamento Básico no Brasil Plansab (BRASIL, 2011) adotou uma conceituação que considera, além da oferta do serviço 
(infraestrutura), aspectos referentes ao uso da solução ofertada e à qualidade desta oferta (aspectos socioeconômicos e culturais), destacando, entretanto, que a natureza dos serviços de drenagem e manejo de águas pluviais não permite a utilização de indicadores semelhantes. Observa-se, portanto, não haver consenso em relação ao conceito de déficit na drenagem urbana e aos indicadores de avaliação dos sistemas de drenagem.

A avaliação do sistema de drenagem e manejo de águas pluviais é mais complexa, devido à impossibilidade de analisar seu funcionamento ou eficiência apenas por índices de cobertura de rede ou pelo atendimento per capita: a existência de rede não garante a ausência de alagamentos, assim como a avaliação per capita não é possível uma vez que a drenagem é analisada em contexto de bacia hidrográfica contribuinte. Por essas razões, o SNIS (BRASIL, 2010b) não apresentou, até agora, diagnóstico sobre os serviços públicos de drenagem baseado em conceito de indicadores, e tampouco é possível analisar o conceito de déficit na drenagem apenas com esses elementos.

O Plano Nacional de Recursos Hídricos PNRH (BRASIL, 2006) apresentou alguns indicadores de drenagem baseados na existência de estruturas de drenagem, mostrando que $79 \%$ dos municípios brasileiros dispunham de sistema de drenagem em 2006. A simples existência do sistema de drenagem nada representa em relação às questões relacionadas a ele, uma vez que os maiores problemas de escoamento das águas pluviais, geralmente, estão associados à existência de grandes estruturas de drenagem, abertas ou fechadas. Paradoxalmente, onde há mais infraestrutura de drenagem, parece ser 0 lugar em que mais ocorrem falhas. Todos os indicadores apresentados pelo $\mathrm{PNRH}$ estão relacionados à existência de estruturas de drenagem do tipo canalização (aberta ou fechada, em forma de galerias) ou bacias de detenção, o que indica um viés conceitual na drenagem para medidas estruturais. O viés (ou falha) conceitual do PNRH continua na apresentação dos indicadores de problemas de inundação, não havendo distinção entre inundações ribeirinhas e alagamentos ou inundações urbanas, cujos mecanismos de formação são completamente diferentes em sua relação com o desenvolvimento urbano, conforme apresentado por Tucci (2002).

Desta forma, esse artigo busca estabelecer uma definição para déficit em drenagem e manejo de águas pluviais urbanas que contemple outros aspectos do funcionamento dos sistemas de drenagem, além do estabelecimento de indicadores de existência (cobertura) ou atendimento per capita.

\section{FUNDAMENTAÇÃO TEÓRICA}

Os indicadores em saneamento básico têm sido utilizados para diversas finalidades, podendo ser destacadas a avaliação (diagnóstico) na prestação dos serviços (BRASIL, 2010b) e o estabelecimento de regras para priorização de políticas públicas, como o Índice de Salubridade Ambiental adotado pela Prefeitura Municipal de Belo Horizonte (BELO HORIZONTE, 2008), estando sempre vinculados aos conceitos de déficit ou de eficiência. No caso da drenagem urbana, Kolsky e Butler (2002) destacam que a própria definição de desempenho não é simples, dependendo, inclusive, da identificação dos objetivos do sistema de drenagem (funções de drenagem, composição paisagística, manutenção de processos hidrológicos, entre outras) e da forma como a comunidade percebe a melhoria da qualidade de vida promovida por ele.

Os sistemas de drenagem de águas pluviais, como definido na maioria dos manuais técnicos, estão associados a obras de canalização (BOTELHO, 1998; DAEE/CETESB, 1980), mais recentemente combinados com estruturas de armazenamento para amortecimento de vazões. Seu dimensionamento é feito com base em alguns elementos principais: chuva de projeto (baseado em uma curva Intensidade-Duração-Frequência), características da área contribuinte (expressas pelo coeficiente de escoamento superficial e pelo tempo de concentração) e tempo de retorno de projeto. A partir da estimativa da vazão máxima, com base na equação do Método Racional, utilizase a equação de Manning para determinar as dimensões que comportam a vazão calculada, do ponto de vista hidráulico.

Essa forma de abordagem dos sistemas de drenagem resulta na seguinte conclusão: os 
sistemas de drenagem de águas pluviais foram planejados e dimensionados para falhar. Tal afirmação pode ser avaliada a partir dos seguintes elementos principais:

1) sem outras interferências, o sistema de drenagem deverá falhar para eventos de tempo de recorrência superiores ao tempo de retorno de projeto (Tr). Essa conclusão está, obviamente, associada ao risco assumido de falha, associado ao $\mathrm{Tr}$;

2) as curvas IDF são obtidas a partir de análise estatística de dados de chuva, que apresentam alto grau de incerteza, especialmente para áreas distantes das grandes cidades. De fato, diversas cidades brasileiras ainda utilizam as equações apresentadas por Pfafstetter em 1957 (PFAFSTETTER, 1982) para calcular as chuvas de projeto e poucas são aquelas que atualizaram suas curvas IDF. Nesse caso, destaca-se, ainda, que o crescimento das cidades pode provocar mudanças nos padrões de chuva, com aumento da intensidade dos eventos extremos;

3) o cálculo da vazão de projeto utiliza o valor do Coeficiente de Escoamento Superficial (C): esse valor apresenta, em geral, um retrato do instante em que está sendo avaliado o projeto do sistema de drenagem, o qual, com o passar do tempo, aumenta com a ampliação da impermeabilização do solo. Deve-se observar, ainda, que esse valor não consegue, em grande parte dos casos, retratar a real característica da bacia, uma vez que o $C$ não é função apenas do uso e ocupação do solo e que as tabelas utilizadas uniformizam seu valor apenas para essa característica. Ressaltase, também, que as condições de uso e ocupação reais, normalmente, apresentam maiores taxas de impermeabilização do que aquelas de projeto (previstas em Planos Diretores Urbanos);

4) 0 cálculo do tempo de concentração da bacia (tc) é feito a partir de equações empíricas que, dificilmente, representam as condições de projeto e a redução do tc pelo processo de ampliação da urbanização. Nesse caso, destaca-se a equação de Kirpich, que foi desenvolvida para bacias rurais, mas que é comumente utilizada nas áreas urbanas;

5) os sistemas de drenagem são dimensionados para transportar água de chuva, mas 0 que se observa, efetivamente, é uma grande mistura da água de chuva, de esgotos, sedimentos e resíduos sólidos (alguns de grandes dimensões como móveis), cujo resultado é a obstrução ou o aumento da rugosidade das redes. Neves (2006), por exemplo, apresenta uma caracterização dos resíduos sólidos encontrados na rede de drenagem em Porto Alegre.

A maioria dos manuais de projeto de sistemas de drenagem de águas pluviais no Brasil apresenta afirmações que conduzem às seguintes interpretações:

- a melhor drenagem é aquela que escoa a água da chuva o mais rápido possível para jusante;

- uma boa solução para integração urbana é por meio de avenidas de fundo de vale, associadas à canalização dos corpos d'água;

- o fechamento do canal permite ganhar espaço sobre o rio, esconde a poluição e promove a melhoria urbana local, a partir de obras de urbanização dos corpos d'água.

Esse tipo de abordagem conduziu a um processo sistemático de canalização e recobrimento dos corpos d'água, como uma forma de livrar a cidade de um elemento que provoca a degradação do ambiente. A solução se assemelha ao tradicional "varrer para baixo do tapete".

No Brasil, essa discussão ganhou espaço a partir do final dos anos 80 , mas foi incorporada, de fato, apenas no final dos anos 90, especialmente no meio acadêmico. A percepção da complexidade dos sistemas e da insustentabilidade na abordagem tradicional gerou um grande esforço por mudanças conceituais. Esse fato está, de certa forma, traduzido na Lei Nacional de Saneamento Básico (BRASIL, 2007, artigo 3o., inciso I, alínea d) quando se coloca como um dos componentes do saneamento básico 
a "drenagem e manejo de águas pluviais urbanas". Formalmente, o termo "manejo" aparece pela primeira vez associado à drenagem, quebrando o paradigma de que drenar é necessário. Apresentase a noção da necessidade de gerir ou manejar as águas urbanas como importante elemento da paisagem uma vez que os corpos d'água, inegavelmente, estão integrados à cidade, valorizando ou deteriorando o espaço. Com essa nova abordagem, busca-se visualizar os processos naturais, em particular o ciclo hidrológico, e os impactos que a cidade causou sobre eles. Busca-se, portanto, a compensação de efeitos da urbanização ou, ainda, uma forma de urbanização que minimize os impactos sobre os processos naturais (TUCCI; BERTONI, 2003).

As cidades brasileiras, em geral, têm sofrido, sistematicamente, com as falhas dos sistemas de drenagem, com grandes prejuízos materiais e risco à saúde e à vida da população, fortalecendo o senso comum da necessidade de ampliação de galerias e execução de obras de canalização e retificação de corpos d'água. Os conceitos de déficit no sistema de drenagem pluvial, na visão tradicional, estão associados aos alagamentos causados pela inexistência de redes, sua insuficiência ou obstrução (os indicadores do PNRH estão sempre associados à existência de redes de drenagem). A Figura 1 apresenta as alterações provocadas pela urbanização sobre os hidrogramas de cheias, considerando a abordagem tradicional da drenagem urbana, por meio de canalizações. Pode ser observado que o crescimento da cidade cria e amplia pontos de alagamentos e que o tratamento dos problemas por canalização apenas transfere os volumes de um ponto a outro, criando uma falsa sensação de segurança, o que permite a ocupação cada vez mais próxima dos corpos d'água.

Figura 1: A abordagem tradicional da drenagem urbana e sua relação com os alagamentos. Fonte: adaptado pelos autores com base em Tucci e Bertoni (2003).

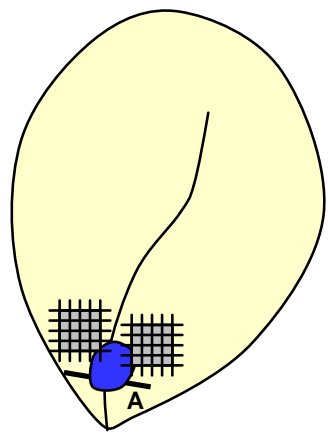

Estágio 1

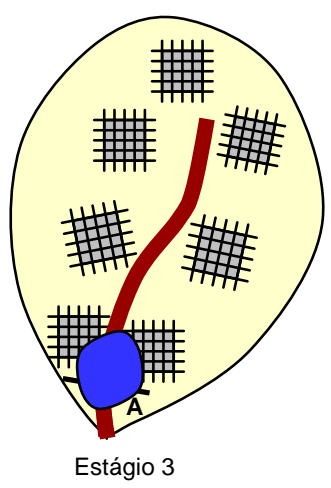

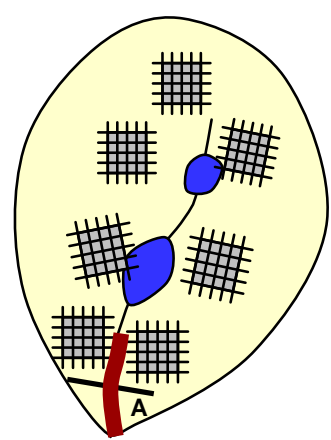

Estágio 2

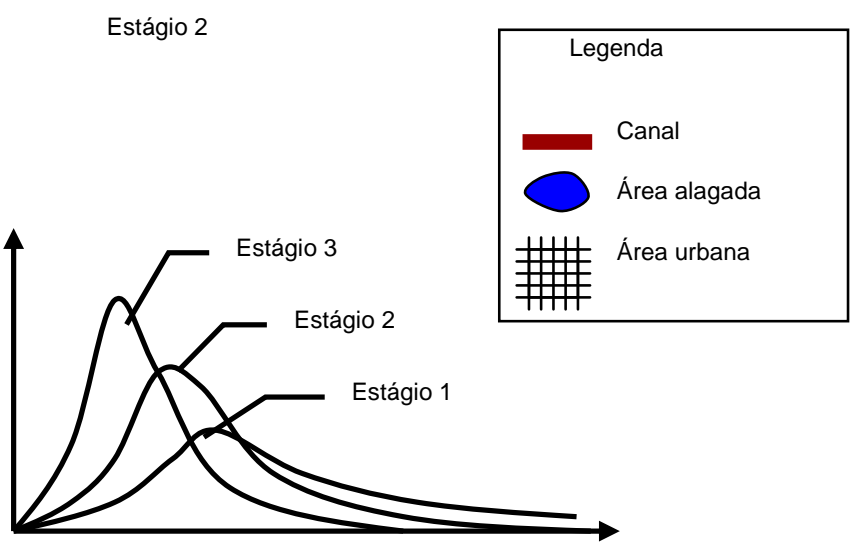


A associação das falhas no sistema de drenagem com a ausência ou insuficiência de redes é proveniente do tratamento que o sistema de drenagem pluvial sempre recebeu, ou seja, como um acessório do sistema viário, cujo planejamento, execução e gestão estão vinculados aos órgãos municipais de obras, não havendo um planejamento sistemático da drenagem, com visualização da bacia hidrográfica como elemento de análise. Nessas situações, o conceito de déficit está associado, tão somente, à ausência ou insuficiência dos canais de drenagem pluvial, indicando sua implantação ou ampliação.

Numa perspectiva mais abrangente, a partir da percepção da bacia hidrográfica como sistema (já determinados na Lei das Águas [BRASIL, 1997] e na Lei Nacional de Saneamento Básico [BRASIL, 2007]), o conceito do déficit no sistema de drenagem pluvial se associa com o próprio conceito do sistema de drenagem $e$ manejo de águas pluviais. Ao visualizar a complexidade desse sistema e as suas relações e interferências com os demais elementos do espaço urbano, com importante impacto na qualidade de vida, percebe-se a necessidade de analisar os tipos de falhas associados aos sistemas de drenagem e as relações que geram tais falhas. Dessa forma, é necessário destacar que:

1) nem sempre quem gera $o$ alagamento sofre suas consequências diretas, uma vez que o aumento das vazões tem impacto à jusante de sua geração e está associado à impermeabilização do solo, determinada pelos padrões atuais de uso e ocupação do solo. Da mesma forma, nem sempre quem sofre com os alagamentos teve responsabilidade direta com a ampliação do escoamento superficial natural;

2) o processo de ampliação da cheia natural, provocado pela urbanização, pode ser controlado no próprio local de geração, por meio de técnicas de desenvolvimento de baixo impacto e de medidas compensatórias dos efeitos da urbanização sobre o ciclo hidrológico;
3) o espaço natural tem pontos, também naturais, de alagamentos e sua ocupação é garantia de falhas futuras no sistema de drenagem;

4) a abordagem tradicional, com base na eficiência hidráulica de redes, transfere impactos para jusante;

5) o dimensionamento de redes considera risco de falha ao utilizar o conceito de Tempo de Retorno para projeto. Dessa forma, os projetos de drenagem já estão associados com uma garantia de falha para eventos superiores aos de projeto (além de outros fatores, já discutidos acima);

6) a urbanização pode gerar mudanças locais de clima (mudanças nas relações intensidade-duração-frequência),

modificando o regime pluviométrico local $\mathrm{e}$, consequentemente, modificando as relações de risco de falha do sistema;

7) a base de informações da infraestrutura da cidade é essencial para a gestão das águas pluviais;

8) a relação com outros elementos (esgotos, sedimentos e resíduos sólidos) é fundamental para o funcionamento dos sistemas de drenagem pluvial.

Considerando-se os elementos apresentados, observa-se a necessidade de analisar o conceito de déficit nos sistemas de drenagem e manejo de águas pluviais em relação a uma série de elementos que extrapola apenas as questões hidráulicas. Um conceito mais abrangente deve considerar a cobertura do sistema, a tecnologia utilizada para a gestão das águas pluviais, a informação disponível, a degradação dos corpos d'água e as estruturas técnico-institucionais.

\section{METODOLOGIA}

Para a elaboração deste artigo, foi realizada revisão bibliográfica $e$ análise da legislação pertinente ao funcionamento dos sistemas de drenagem e manejo de águas 
pluviais, considerando a experiência dos autores na área. Em função da evolução conceitual relativa ao tema, especialmente aquelas introduzidas pela Lei Nacional de Saneamento Básico (BRASIL, 2007), as discussões conduzidas adotam a seguinte terminologia:

1) sistemas de drenagem (ou sistemas de drenagem pluvial): quando estiver sendo abordado o sistema tradicionalmente utilizado, com base na eficiência hidráulica e com a noção específica (e explícita) de drenagem, sem preocupação com outras funções dos sistemas de drenagem urbana;

2) sistemas de drenagem e manejo de águas pluviais: quando estiver sendo abordada uma nova concepção, que busca a integração das águas pluviais ao ambiente urbano, de forma mais ampla.

A definição do déficit em drenagem urbana e manejo de águas pluviais levou em consideração a evolução conceitual observada na abordagem da drenagem pluvial, com a introdução em Lei de aspectos multifuncionais do sistema e de integração em âmbito urbano (recorte urbanístico) e ambiental (recorte da bacia hidrográfica). A conceituação apresentada indica, portanto, caminhos para a definição de indicadores que permitam avaliar o estado (diagnóstico) de tais sistemas e metodologias de priorização de ações em políticas públicas, extrapolando a simples análise de cobertura de redes e de ocorrência de alagamentos ou inundações. Observa-se, igualmente, a indicação da diferenciação dos mecanismos de formação dos problemas urbanos relacionados ao escoamento superficial, como as inundações ribeirinhas e cheias ou alagamentos urbanos (TUCCI, 2002), que também devem estar representados nos indicadores.

Para a discussão dos resultados, abordagens diferentes e complementares do déficit foram estabelecidas:

- déficit de informação, considerando o tipo, a qualidade e acessibilidade da informação sobre os sistemas de drenagem e manejo de águas pluviais, e a necessidade desta informação para intervenção adequada;
- déficit qualitativo, considerando que as intervenções na drenagem urbana têm tido exclusiva preocupação com aspectos de quantidade (vazões máximas e, eventualmente, volumes), provocando a degradação das águas nos corpos d'água urbanos;

- déficit tecnológico, considerando que a solução para resolver problemas de escoamento das águas pluviais tem sido, exclusivamente, em forma estrutural do tipo canalização e, eventualmente, amortecimento;

- déficit técnico-institucional, considerando a fragilidade institucional para tratar de forma integrada as questões de drenagem e manejo de águas pluviais;

- déficit de cobertura, considerando a existência adequada das redes, onde elas se fazem necessárias (a ausência de rede não significa, necessariamente, déficit);

- déficit de concepção e comunicação (ou participativo), considerando que as soluções para os problemas de drenagem, de maneira geral, são concebidas exclusivamente em ambiente técnico, sem considerar as efetivas demandas da sociedade.

\section{RESULTADOS E DISCUSSÃO}

O déficit na drenagem urbana está relacionado a vários aspectos técnicos, legais, sociais, financeiros e culturais, relacionados à realidade local, os quais dificultam a adoção de novos conceitos, como destacam Goldenfum et al. (2007). Desta forma, o desenvolvimento de planos integrados (especialmente os de saneamento básico e desenvolvimento urbano) esbarra em problemas como o baixo nível de controle sobre a expansão urbana e a deficiência da informação. Essas questões estão representadas nos diferentes aspectos do déficit em drenagem, que serão discutidos a seguir.

\subsection{Déficit de informação}

No que se refere à informação, o déficit está associado ao pouco conhecimento efetivo dos sistemas de drenagem, incluindo as bacias hidrográficas contribuintes como um todo. Assim, o déficit de informação está relacionado: 
1) à caracterização das bacias e subbacias urbanas, incluindo detalhamento da hidrografia natural;

2) ao cadastro de redes de drenagem e dos demais elementos da infraestrutura urbana (esgotamento sanitário, abastecimento de água, telefonia, eletricidade, gás, entre outros). Essa informação é necessária para analisar o funcionamento do sistema e para o planejamento de intervenções que se façam necessárias;

3) ao uso e ocupação do solo: geralmente, a ocupação real promove maiores taxas de impermeabilização do que o previsto nos instrumentos do planejamento urbano, como mostrou Carvalho (2012), os quais são utilizados no projeto dos sistemas de drenagem. Entretanto, dificilmente, essa informação está disponível;

4) aos indicadores socioambientais: as intervenções nos sistemas de drenagem $e$ manejo de águas pluviais devem ser priorizadas de acordo com indicadores associados aos riscos que a sociedade está sujeita no caso da ocorrência de eventos extremos vinculados à rede de drenagem. No caso dos sistemas de drenagem, esses indicadores podem estar associados a: densidade populacional, estado de degradação/salubridade do ambiente, ocorrência de alagamentos (com definição de nível e frequência), entre outros. Entretanto, esse tipo de informação, dificilmente, está disponível ou é levado em consideração para avaliação dos sistemas de drenagem de águas pluviais, apesar de sua caracterização ser importante para avaliar a deficiência na infraestrutura urbana.

Nesse aspecto do déficit, Goldenfum et al. (2007) destacam, especialmente, a precariedade das informações hidrológicas e hidráulicas que permitam avaliar as condições atuais (diagnóstico) e os cenários futuros de planejamento e intervenção. Tal aspecto está mais relacionado ao Poder Público, responsável não só por manter um acervo que permita intervenções adequadas na infraestrutura urbana (só é possível intervir adequadamente se o sistema é bem conhecido), mas também por fomentar 0 debate junto à sociedade com base em informações consistentes, realistas e que possibilitem a avaliação de todas as alternativas possíveis (não só das soluções tradicionais).

\subsection{Déficit qualitativo}

No que se refere à degradação dos corpos d'água, o déficit está associado à própria qualidade das águas pluviais. Até recentemente, havia o entendimento de que as águas pluviais eram mais limpas. Entretanto, alguns autores como Chebbo et al. (2001), Neves (2006) e Pimentel (2009), citados anteriormente, mostraram que a qualidade da água proveniente do escoamento superficial também é bastante ruim, contendo grande quantidade de metais pesados, óleos, graxas, sedimentos e todo tipo de resíduo sólido urbano, sobretudo durante o período inicial da chuva. Associa-se a esses elementos o lançamento de esgotos domésticos ou industriais diretamente nos corpos d'água urbanos ou, ainda, na própria rede de drenagem. Neste sentido, o déficit qualitativo do sistema de drenagem e manejo de águas pluviais se refere à combinação do déficit aos demais elementos do saneamento básico e à baixa qualidade do escoamento superficial provocada pela lavagem das superfícies.

A avaliação desse tipo de déficit terá relação direta com o funcionamento hidráulico das redes de drenagem, uma vez que a presença de sedimentos, resíduos sólidos e esgotos na rede de drenagem provoca mudanças importantes no funcionamento da drenagem, a saber:

1) a presença de sedimentos e resíduos sólidos obstrui a rede e provoca aumento na rugosidade, diminuindo a capacidade hidráulica de transporte de vazão e, consequentemente, provocando insuficiência das redes;

2) a degradação dos cursos d'água, em função do déficit qualitativo, provoca uma sensação de rejeição por parte da sociedade, que passa a entender esse ambiente como um "esgoto a céu aberto" e não mais como um "curso d'água". Desta forma, a tendência é de maior aceitação 
ao conceito "drenar" do que ao conceito "manejar" as águas de chuva.

\subsection{Déficit tecnológico}

Tradicionalmente, no Brasil, a tecnologia utilizada para o manejo das águas pluviais é a drenagem (por condutos) propriamente dita, ou seja, parte-se do pressuposto que "drenar é necessário", conforme já foi discutido anteriormente. A dificuldade de relacionar a forma de urbanização com os problemas associados à falha nos sistemas de drenagem conduz a um tratamento pontual dos alagamentos (conforme mostrado na Figura 1). A tecnologia utilizada é sempre a de canalização do escoamento superficial, com os sistemas de microdrenagem contribuindo para os sistemas de macrodrenagem que, por sua vez, têm a função de eliminar, o mais rapidamente possível, a água dos centros urbanos. Esse tipo de abordagem apresenta suas limitações, uma vez que apenas transfere os alagamentos para jusante, não havendo sustentabilidade em longo prazo. Neste sentido, pode-se definir o déficit tecnológico a partir da ausência de utilização de soluções e técnicas de drenagem e manejo de águas pluviais mais integradas ao contexto das cidades, como as soluções compensatórias do efeito da urbanização ou, ainda, as técnicas de desenvolvimento urbano de baixo impacto (LID - Low Impact Development).

Nesse caso, é interessante observar que já existe um importante reconhecimento das limitações tecnológicas dos sistemas tradicionais, mas que ainda não se traduz em incorporação efetiva de novas tecnologias.

Em 2006, o Ministério das Cidades e o Ministério da Integração Nacional lançaram o "Programa 1138 - Drenagem Urbana e Controle da Erosão Marítima e Fluvial: manual para apresentação de propostas" ${ }^{2}$ (BRASIL, 2009, 2010a), trazendo uma série de diretrizes relacionadas à concepção dos sistemas de drenagem como condicionantes para conseguir

2 A versão do Programa 1138 datada de 2006 era intitulada "Programa 1138 - Drenagem Urbana Sustentável: manual para apresentação de propostas", sendo posteriormente complementada para incluir o controle de erosão, que se tornou mais genérica nos aspectos relacionados à drenagem urbana. financiamento do Governo Federal, com vistas à intervenção em drenagem pluvial. Apesar de deixar claro que as soluções baseadas em redes ou em canalização de cursos d'água (base em eficiência hidráulica) não devem ser prioridade, sendo sua utilização aceita apenas em casos específicos onde as técnicas compensatórias não sejam possíveis, não houve mudança efetiva na prática, e várias cidades brasileiras continuam fazendo intervenção, com recursos desses ministérios, com base nas mesmas técnicas tradicionais de drenagem.

Evidentemente, a mudança da solução tecnológica esbarra em questões como a interação com outros elementos do saneamento básico (e, consequentemente, os aspectos de qualidade da água limitam determinados tipos de solução), a capacitação técnica para projetos de dispositivos compensatórios, a inexistência de instrumentos de avaliação sistemática das soluções adotadas, a fragilidade institucional (déficit técnico-institucional) para avaliar medidas distribuídas na bacia, entre outros, como destacado por Goldenfum et al. (2007).

\subsection{Déficit técnico-institucional}

As mudanças de paradigmas no tratamento das questões relacionadas à infraestrutura urbana esbarram em outra questão importante: o déficit técnico-institucional em relação às águas pluviais. $\mathrm{Na}$ maioria dos municípios brasileiros, com poucas exceções (como Porto Alegre), a drenagem das águas pluviais é de responsabilidade dos órgãos municipais de obras e/ou infraestrutura viária. Desta forma, o sistema de drenagem passa a ser visto como "um apêndice" do sistema viário e não como um elemento da infraestrutura que deve ser trabalhado com atenção especial. Via de regra, o corpo técnico desses órgãos não tem a atualização necessária para fazer uma abordagem do manejo das águas pluviais dentro de uma visão mais integral do sistema, conforme a definição de Porto et al. (1997). Outro aspecto que merece destaque é o fato de não haver atualização do corpo técnico permanente, já que parte significativa dos técnicos municipais não pertence ao quadro permanente das prefeituras, resultando em dificuldade de continuidade das políticas públicas urbanas. 
Mesmo onde há estrutura institucional específica para a gestão das águas pluviais, não há consenso sobre as responsabilidades compartilhadas. Goldenfum et al. (2007) destacam a dificuldade de integração entre órgãos do mesmo nível de governo para a gerenciamento dos sistemas de drenagem em Porto Alegre, no caso de estruturas que compartilham o espaço urbano e as funções (e.g. bacias de detenção em praças).

Ainda em relação ao déficit institucional, o Ministério das Cidades vem tratando a questão do planejamento urbano, em todos os seus aspectos, como prioridade. Entretanto, o alcance desse planejamento, na maioria das cidades brasileiras, é limitado no que se refere ao manejo das águas pluviais. Os Planos Diretores das Cidades, em geral, apesar de terem um forte discurso ambiental, ignoram o traçado natural dos corpos d'água, havendo poucas restrições para ocupação de áreas de risco relacionado às águas pluviais (FERNANDES et al., 2011). No mesmo sentido, os Planos Diretores de Drenagem Urbana (ou Planos Municipais de Saneamento Básico), obrigatórios para demandar recursos federais, ainda têm tratado a questão apenas do ponto de vista das obras de canalização. Poucos Planos Diretores de Drenagem Urbana têm incorporado a ideia da conservação do ciclo hidrológico natural, restringindo a ocupação das áreas de risco ou exigindo a compensação dos efeitos da urbanização sobre o ciclo hidrológico. Neste aspecto, deve-se destacar que 0 dimensionamento de obras de canalização para a drenagem pluvial é garantia de falha, pela própria definição do tempo de retorno de projeto das obras e por outros aspectos já discutidos anteriormente.

Deve-se considerar, ainda, a dificuldade das municipalidades em observar as regras da expansão urbana, ainda que não muito bem definidas no que se refere aos processos hidrológicos, estabelecidas nos Planos Diretores. Como bem observam Goldenfum et al. (2007), trabalhar a mínima interferência no ciclo hidrológico em escala de bacia torna-se mais difícil quando apenas uma parte da bacia hidrográfica (a chamada cidade formal) segue as regras definidas no planejamento, havendo parcela significativa de expansão espontânea, sem observância de regras ou padrões urbanos.

\subsection{Déficit de cobertura}

Quanto à abrangência da rede, tem-se o déficit de cobertura, que se relaciona ao alcance do sistema de drenagem e sua eficiência no sentido de minimizar os riscos que a sociedade está sujeita no que se refere aos alagamentos. Esses riscos estão associados à ocorrência de eventos de alagamentos, mas também a questões sanitárias, uma vez que, geralmente, as águas nos sistemas de drenagem possuem alto grau de poluição/contaminação. Um sistema de drenagem urbana e manejo de águas pluviais, avaliado em toda a sua complexidade, deve ser composto aqui sendo destacados apenas os aspectos vinculados à tecnologia para drenagem e manejo das águas pluviais - por:

1. sistemas de micro e macro-drenagem, incluindo as sarjetas nas ruas, as galerias de águas pluviais e as estruturas de acesso (bocas de lobo, poços de visita etc.);

2. bacias de detenção e retenção de águas pluviais;

3. bacias, trincheiras, valos e poços de infiltração de águas pluviais;

4. pavimentos permeáveis;

5. parques lineares ao longo dos corpos d'água, associados às zonas de maior risco de alagamentos;

6. elementos de controle da geração de escoamento superficial na fonte (áreas permeáveis nos lotes, microrreservatórios de detenção, elementos de infiltração no lote etc.).

Destaca-se, nesse caso, que a cobertura dos sistemas de drenagem, hoje, está fortemente associada apenas à primeira técnica apresentada e, em alguns casos, à utilização da segunda. Normalmente, os sistemas de drenagem têm sido implantados apenas quando iniciam os problemas localizados de alagamentos, não havendo avaliação prévia de sua necessidade.

Considerando o próprio conceito de sistema de drenagem, apresentado por Porto et al. (1997), o déficit de cobertura deve ser analisado a partir de indicadores de falha do sistema 
(funcionamento hidráulico associado a outros elementos da infraestrutura) e de degradação (ou salubridade) dos corpos d'água. Neste aspecto, devem ser utilizados indicadores que relacionem a abrangência, a frequência e a magnitude das falhas, conforme apresentado por Holz (2010), e seus impactos (prejuízos financeiros, risco à vida, à saúde e ao ambiente, entre outros) em relação à infraestrutura existente e ao uso e ocupação do solo, conforme apresentado no Plano Municipal de Saneamento de Belo Horizonte.

\subsection{Déficit de concepção e comunicação (ou participativo)}

Por fim, podem-se acrescentar, para análise do déficit, os elementos relacionados à abordagem técnica tradicionalmente utilizada. Nesse caso, pode-se definir como déficit de concepção e comunicação aquele relacionado a dois elementos principais:

1) à ideia de que a solução técnica (de engenharia) é sempre melhor do que a solução concebida de forma participativa (envolvendo a sociedade);

2) à rejeição popular a medidas de adaptação não estruturais ou estruturantes.

O primeiro elemento conduz a uma rejeição pela sociedade de soluções que poderiam ser tecnicamente boas se houvesse um processo de participação na análise dos problemas e concepção das soluções. Aparentemente, há um consenso no meio técnico de que as boas soluções podem ser concebidas, apenas, a partir do conhecimento técnico de engenharia. Esse caso pode ser muito bem ilustrado nas escadarias drenantes de Salvador, como destacou Mangieri (2012), onde houve rejeição das soluções por detalhes de concepção que não foram avaliados na fase de projeto.

O segundo elemento, também associado a outros aspectos do déficit, vincula-se ao estado atual dos cursos d'água urbanos e a uma expectativa de eliminação desse elemento (o rio em si) de degradação: não há percepção da possibilidade de reinserção da água como elemento de composição (agradável) da paisagem. Há uma forte demanda da sociedade pela eliminação imediata dos riscos relacionados à chuva, bem representada no noticiário cotidiano em períodos chuvosos (SILVEIRA; PARREIRAS, 2011), sem a percepção de que a condição atual é resultante de um processo histórico de décadas, conforme está bem ilustrado em Polignano (2008).

A aversão ao risco e a rejeição a soluções não estruturais estão bem representadas nas medidas de adaptação (também componentes do sistema de drenagem e manejo de águas pluviais) adotadas, recentemente, em Belo Horizonte. A percepção da incapacidade de combater as cheias e da insustentabilidade das soluções tradicionais no longo prazo levou a municipalidade a elaborar a Carta de Inundações (BELO HORIZONTE, 2009) e, a partir dela, informar a sociedade, por meio da instalação de placas de sinalização nos locais de risco (comunicação do risco). A medida foi imediatamente rejeitada pela população, que esperava por ações estruturais imediatas, como ampliação dos canais e galerias, como forma de preparação da Cidade para os períodos chuvosos, cobrando soluções amplas e seguras em curto espaço de tempo. Destaca-se, nesse caso, que há uma tendência a esperar que as cidades estejam "preparadas estruturalmente" para garantir que, durante eventos extremos, não ocorram alagamentos ou inundações. Um exemplo do que tem sido mostrado com frequência na mídia em geral pode ser encontrado em Silveira e Parreiras (2011) sobre o combate a enchentes: todas as medidas de preparação da cidade demandadas pela sociedade se referem a obras de canalização como solução, não havendo compreensão pelas medidas não estruturais ou estruturantes, o que denota a incapacidade (ou déficit) de concepção e comunicação das alternativas à canalização.

\section{CONCLUSÃO}

Tendo em vista esses diferentes e complementares conceitos de déficit associados às águas pluviais, entende-se, portanto, que 0 déficit da drenagem está relacionado à degradação da água no espaço urbano e aos riscos que a sociedade está sujeita na eventualidade de ocorrência de eventos de alagamentos. Destaca-se que o conceito de déficit relacionado às águas pluviais não é possível de ser estabelecido com a utilização de população 
coberta por redes de drenagem ou por valores per capita. Tratar esse déficit significa trabalhar a valorização da água nas cidades, com a valorização do próprio ambiente, utilizando-se soluções que sejam integradas a esse ambiente, que minimizem os impactos sobre os processos naturais, em geral, e sobre o ciclo hidrológico, em particular, e que permitam, sobretudo, a convivência da população com esses processos naturais. A percepção dos processos naturais por parte do cidadão deve fazer com que ele se sinta mais responsável pelas falhas do sistema.

Deve-se observar que a conceituação aqui apresentada não esgota o assunto. Não foram levantados, por exemplo, os aspectos relacionados à questão legal, o que deve abrir um novo espaço para discussão. Há uma série de instrumentos legais que interferem na questão das águas pluviais urbanas - Código Florestal, Lei de Parcelamento do Solo Urbano, Lei Nacional de Saneamento Básico, Estatuto da Cidade, Planos Diretores de Desenvolvimento Urbano ou Municipal, entre outros -, e que não têm sido efetivamente observados. Para citar apenas um exemplo, tanto o Código Florestal quanto a Lei de Parcelamento do Solo Urbano tratam da restrição à ocupação de bordas de cursos d'água e de encostas, mas essas áreas continuam sendo sistematicamente ocupadas, tanto pela cidade oficial/formal (com registro e licenças municipais), quanto pela cidade não-oficial/informal (de ocupações espontâneas), o que mostra a deficiência na observância dos instrumentos da política urbana.

$\mathrm{Da}$ mesma forma, as questões relacionadas aos aspectos ecológicos, como alteração do ambiente natural e consequente perda de biodiversidade, abre um novo espaço de discussão sobre os conceitos de déficit na drenagem urbana. Como foi ressaltado por Burns et al. (2012), as mudanças nos processos hidrológicos (vazões, volumes, tempos de resposta do escoamento) e na qualidade da água não estão sendo tratadas de forma integral pelas soluções adotadas na drenagem urbana. As soluções tradicionais priorizam o escoamento, enquanto as soluções compensatórias priorizam a qualidade da água, apesar de no Brasil o dimensionamento das soluções compensatórias estar sendo realizado apenas com base no controle da vazão de pico e do volume, conforme metodologia apresentada por Silveira e Goldenfum (2007).

Segundo Burns et al. (2012), apesar dos avanços das últimas décadas, com o reconhecimento das questões de qualidade, tanto a abordagem tradicional de eficiência hidráulica quanto o controle da qualidade da água do escoamento ainda falham por considerar aspectos ecológicos apenas com base no regime de vazões. Nesse sentido, a ampliação da discussão conceitual sobre o déficit na drenagem urbana deve considerar os efeitos de escala nos processos (quantitativos e qualitativos) com abordagem ecológica, incorporando os efeitos de escala das soluções adotadas (parcela, microdrenagem, macrodrenagem, bacia hidrográfica), conforme destacado por Marsalek e Schreier (2009) e Burns et al. (2012).

Historicamente, as soluções tradicionais, baseadas em eficiência hidráulica, focam a grande escala, ou seja, os efeitos na macrodrenagem, o que parece indicar um importante aspecto do déficit (concepção). De acordo com Burns et al. (2012), os estudos mais recentes mostram que, aparentemente, recuperar os balanços hídricos em escala local pode ser uma estratégia para a escala de bacia no sentido da recuperação das condições naturais, mas ainda há necessidade de aprofundamento no assunto, especialmente no que se refere aos arranjos institucionais para tratar as questões de uso difuso e de aspectos de manutenção das soluções adotadas.

Este artigo buscou, portanto, estabelecer um novo foco de discussão para definição de déficit em drenagem urbana e manejo de águas pluviais, como uma forma de contribuir para o estabelecimento de critérios de avaliação desses sistemas. Observa-se que não há um aspecto único a ser observado, em função da complexidade do sistema e da dificuldade de tratálo de forma integral, o que levou à fragmentação das abordagens.

\section{REFERÊNCIAS}

BELO HORIZONTE. Plano Municipal de Saneamento de Belo Horizonte 2008/2011. Belo 
Horizonte: Prefeitura Municipal de Belo Horizonte, 2008.

. Carta de Inundações de Belo Horizonte: identificação de áreas potencialmente susceptíveis. Belo Horizonte: Secretaria Municipal de Políticas Públicas, Superintendência de Desenvolvimento da Capital (Prefeitura Municipal de Belo Horizonte), 2009.

BOTELHO, M. H. C. Águas de chuva: engenharia das águas pluviais nas cidades. 2. ed. São Paulo: Ed. Edgar Blucher Ltda., 1998.

BRASIL. Lei 4.771 de 15 de setembro de 1965. Publicada no Diário Oficial da União em 16/09/1965.

Lei 9.433 de 8 de janeiro de 1997. Publicada no Diário Oficial da União em 09/01/1997.

PNRH - Plano Nacional de Recursos Hídricos. Caderno setorial de recursos hídricos: saneamento. Ministério do Meio Ambiente: Secretaria de Recursos Hídricos. Brasília: MMA, 2006.

. Lei 11.445 de 5 de janeiro de 2007 . Publicada no Diário Oficial da União em 08/01/2007 e retificado em 11/01/2007.

Programa 1138 - Drenagem Urbana e Controle de Erosão Marítima e Fluvial: Manual para apresentação de proposta. Brasília: Ministério da Integração Nacional: Secretaria de Infraestrutura Hídrica, 2009.

Programa 1138 - Drenagem Urbana e Controle de Erosão Marítima e Fluvial: Manual para apresentação de propostas. Brasília: Ministério das Cidades: Secretaria Nacional de Saneamento Ambiental, 2010a.

SNIS - Sistema Nacional de Informações sobre Saneamento. Brasília: Ministério das Cidades: Secretaria Nacional de Saneamento Básico, 2010b.
Panorama do Saneamento Básico no Brasil: elementos conceituais para o saneamento básico. Brasília: Ministério das Cidades, Secretaria Nacional de Saneamento. 2011. V. 1 (versão preliminar). Disponível em: www.cidades.gov.br/ plansab. Acesso em: 17 nov. 2012.

Lei 12.651 de 25 de maio de 2012. Publicada no Diário Oficial da União em 28/05/2012.

BURNS, M. J.; FLETCHER, T. D.; WALSH, C. J.; LADSON, A. R.; HATT, B. E. Hydrologic shortcomings of conventional urban stormwater management and opportunities for reform. Landscape and Urban Planning. v. 105, Issue 3, p. 230-240, April 2012.

CARVAlHO, L. M. Processo de urbanização em área de bacia endorréica: caracterização dos padrões de ocupação dos espaços construídos e dos espaços livres de construção em Maceió/AL. 2012. 141f. Dissertação (Mestrado em Dinâmica do Espaço Habitado) - Pós-Graduação Dinâmica do Espaço Habitado, Universidade Federal de Alagoas, Maceió, 2012.

CARVALHO, P. F.; BRAGA, R. Da negação à reafirmação da natureza na cidade: o conceito de "renaturalização" como suporte à política urbana. Grupo de Pesquisa Análise e Planejamento Territorial - GPAPT. Disponível em: www.rc.unesp.br/igce/planejamento/gpapt/gpapt.ht m. Acesso em: 10 nov. 2009.

CHEBBO, G.; GROMAIRE, M. C.; AHYERRE, M.; GARNAUD, S. Production and transport of urban wet weather pollution in combined sewer systems: the "Marais" experimental urban catchment in Paris. Urban Water, v. 3, n. 1-2, p. 3-15, 2001.

DAEE/CETESB. Drenagem Urbana, Manual de Projeto. 2. ed. São Paulo: DAEE/CETESB, 1980. FERNANDES, N. B.; LINS, R. D. B.; SOUZA, V. C. B. Land planning and urban waters in Maceió/AL. In: INTERNATIONAL CONFERENCE ON URBAN DRAINAGE, 12., 2011, Porto Alegre/Brazil. Proceedings... Porto Alegre: ABRH, 2011.

GOLDENFUM, J. A.; TASSI, R.; MELLER, A.; ALLASIA, D. G.; SILVEIRA, A. L. Challenges for 
the sustainable urban stormwater management in developing countries: from basic education to technical and institutional issues. In: CONFERENCE ON INNOVATIVE TECHNOLOGIES IN URBAN STORM DRAINAGE (NOVATECH), 6., 2007, Lyon. Proceedings... Lyon: GRAIE, 2007.

HOLZ, J. Levantamento e mapeamento do Índice de Risco de Alagamento da bacia do Riacho Reginaldo. 2010. 161f. Dissertação (Mestrado em Recursos Hídricos e Saneamento) - PósGraduação em Recursos Hídricos e Saneamento, Universidade Federal de Alagoas, Maceió, 2010.

IDE, C. N. Qualidade da drenagem pluvial urbana. 1984. 137f. Dissertação (Mestrado em Recursos Hídricos e Saneamento) - Instituto de Pesquisas Hidráulicas, Universidade Federal do Rio Grande do Sul, Porto Alegre, 1984.

KOLSKY, P.; BUTLER, D. Performance indicators for urban storm drainage in developing countries. Urban Water. v. 4, p. 137-144, 2002.

MANGIERI, L. S. G. Avaliação dos sistemas de escadarias e rampas drenantes implantadas em assentamentos espontâneos na cidade do Salvador-Bahia. 2012. 130f. Dissertação (Mestrado em Meio Ambiente, Águas e Saneamento) - Escola Politécnica, Universidade Federal da Bahia, Salvador, 2012.

MARSALEK, J.; SCHREIER, H. Innovation in stormwater management in Canada: the way forward. Water Quality Res. J of Canada, v. 44, n. 1, p. v-x, 2009.

NEVES, M. G. F. P. Quantificação de resíduos sólidos na drenagem urbana. 2006. 194f. Tese (Doutorado em Recursos Hídricos e Saneamento Ambiental) - Instituto de Pesquisas Hidráulicas, Universidade Federal do Rio Grande do Sul, Porto Alegre, 2006.

PFAFSTETTER, O. Chuvas intensas no Brasil. Rio de Janeiro: DNOS, 2.a Ed., 1982.

PIMENTEL, I. M. C. Avaliação quali-quantitativa das águas do riacho Reginaldo e seus afluentes.
2009. 140f. Dissertação (Mestrado em Recursos Hídricos e Saneamento) - Pós-Graduação em Recursos Hídricos e Saneamento, Universidade Federal de Alagoas, Maceió, 2009.

POLIGNANO, M. V. Crônica da morte anunciada de um ribeirão - o Arrudas. Belo Horizonte, 2008.

PORTO, R.; ZAHED F., K.; TUCCI, C.; BIDONE, F. Drenagem Urbana. In: TUCCI, C. E. M. (Org.). Hidrologia: ciência e aplicação. Porto Alegre: Ed. da Universidade: ABRH, 1997. p. 805-847.

SILVEIRA, D.; PARREIRAS, M. BH não está preparada para o período chuvoso. Estado de Minas. $2011 . \quad$ Disponível em: www.em.com.br/app/noticia/gerais/2011/09/16/inte rna_gerais,250987/. Acesso em: 17 out. 2012.

SILVEIRA, A. L. L.; GOLDENFUM, J. A. Metodologia generalizada para prédimensionamento de dispositivos de controle pluvial na fonte. RBRH: Revista Brasileira de Recursos Hídricos, v. 12, n. 2, p. 157-168, 2007.

TUCCI, C. E. M. Gerenciamento da drenagem urbana. RBRH: Revista Brasileira de Recursos Hídricos, v. 7, n. 1, p. 5-27, jan./mar. 2002.

; BERTONI, J. C. (Org.). Inundações urbanas na América do Sul. Porto Alegre: ABRH, 2003. 